\title{
UN MILENIO DE TEXTOS GRECOLATINOS RELATIVOS A LAS ISLAS CANARIAS
}

\author{
Miguel Rodríguez-Pantoja \\ Universidad de Córdoba \\ ca1romam@uco.es
}

\section{RESUMEN}

Texto, traducción y breve comentario de pasajes griegos y latinos, escritos a lo largo de un milenio, en relación con las Islas Canarias, desde el mito a la realidad geográfica, sus distintas denominaciones y su ubicación en el mapa del mundo entonces conocido.

Palabras Clave: Islas Canarias, textos griegos y latinos.

\section{A MILLENNIUM OF GRECO-LATIN TEXTS REGARDING THE CANARY ISLANDS}

\section{ABSTRACT}

Text, translation, and brief commentary of Greek and Latin passages, written throughout a millennium, regarding the Canary Islands, from the myth to the geographical reality, their several names and location in the map of the world known at that time.

KeYWORDS: Canary Islands, Greek and Latin texts.

De acuerdo con el lema de este número de Fortunatae, intento aportar algo al estudio de la historia de las Islas Canarias, en especial la relacionada directamente con el ámbito de la antigüedad clásica, por supuesto, desde el punto de vista filológico, con objeto de no meter la pata contribuyendo al retroceso en vez de al avance, y sin ninguna intención de "sentar cátedra», algo que siempre he rehuido. Propongo, pues, un repaso de la parte textual, que solo ocupa una porción del cuadro: hoy por hoy, a nadie deben caberle dudas de que para avanzar adecuadamente por estos caminos es imprescindible aunar esfuerzos, poniendo a la tarea la mayor cantidad posible de campos de investigación ${ }^{1}$. A este respecto me parece un buen ejemplo el excelente trabajo realizado hace dos decenios por varios autores de reconocida competencia en sus respectivas especialidades, A. Santana Santana, T. Arcos Pereira, P. Atoche Peña y J. Martín Culebras (2002), que ofrecen un panorama multidisciplinar, convincente en la mayoría de sus conclusiones.

Partiendo de estas premisas, propongo poner al alcance de quien se interese por este tema apasionante una recopilación de textos grecolatinos relacionados 
con las Islas Canarias, desde los orígenes hasta finales del siglo IX, la mayor parte de los cuales, como es lógico, han sido ya aportados por los investigadores, aunque no siempre de primera mano, bien transcritos o bien traducidos. Los traigo aquí, pues, una vez más, a partir de ediciones directamente consultadas ${ }^{2}$, ofreciendo mi propia versión, rítmica (o al menos sujeta a alguna convención formal) cuando se trata de versos, y un breve comentario, como mero instrumento de trabajo destinado a facilitar en lo posible que el lector se forme su propia opinión. He procurado, además, situarlos cronológicamente, porque no siempre se tienen en cuenta tales datos, importantes para calibrar de forma adecuada la evolución, o involución, de las ideas a lo largo de este dilatado espacio de tiempo. También indico, cuando me parece relevante, la procedencia geográfica de determinados autores.

Para el nombre global de las islas partimos de un sintagma puramente mítico, el $\mu \alpha \kappa \alpha ́ \rho \omega v v \dot{\sigma o o l}$, que remonta a Hesíodo, o sea, a los albores de la literatura griega, en el siglo VIII a. C., y se mantiene regularme entre los que utilizan esa lengua. Hablando de la «Edad de los héroes», dice Hesíodo, en Los trabajos y los días 167-173:

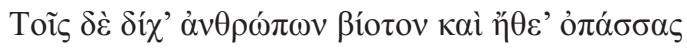

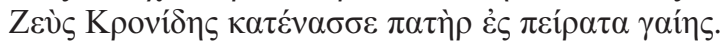

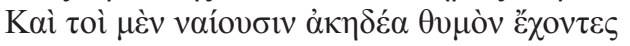

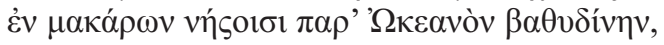

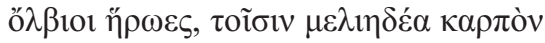

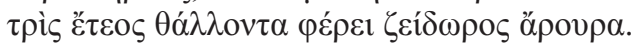

Dándoles vida y sustento distintos al resto de hombres,

Zeus Cronida, su padre, en el fin de la tierra los puso.

Ellos, héroes felices, a salvo de todo desvelo,

en las islas de los bienaventurados habitan,

más allá del océano profundo, y tres veces al año

dulces frutos hermosos les trae un suelo fecundo.

No estará de más recordar que $\mu$ óka $\rho$ se refiere fundamentalmente a las divinidades o a seres más o menos equiparables a ellas, en este caso los héroes: de ahí lo de «bienaventurados». El texto de Hesíodo establece ya una serie de características básicas: son islas, situadas en los confines de la tierra, allende el Océano proceloso, y allí el campo da periódica y espontáneamente frutos agradables de ver y gustar.

Entre los romanos, Cicerón (106-43 a. C.) traduce ese sintagma como beatorum insulae en su tratado De finibus bonorum et malorum 5,53: Ac ueteres quidem

${ }^{1}$ En ello insiste, entre otros, M. Martínez Hernández, destacado investigador de estos temas (1994a: 232).

${ }^{2}$ Normalizo la puntuación y, en los textos latinos, el uso de $u$ para u/v minúscula y $V$ para para u/v mayúscula. 
philosophi in beatorum insulis fingunt qualis futura sit uita sapientium, quos cura omni liberatos, nullum necessarium uitae cultum aut paratum requirentis, nibil aliud esse acturos putant, nisi ut omne tempus inquirendo ac discendo in naturae cognitione consumant. «Y ciertamente los antiguos filósofos imaginan cuál será la vida de los sabios en las islas de los bienaventurados; piensan que estos, liberados de toda preocupación, sin requerir ningún equipamiento o aparato de vida, no harán otra cosa que consumir todo el tiempo investigando y aprendiendo en el conocimiento de la naturaleza»; y también en el Hortensius (frg. 110): Si nobis, cum ex hac uita migrassemus, in beatorum insulis immortale aeuum, ut fabulae ferunt, degere liceret, quid opus esset eloquentia, cum iudicia nulla fierent, aut ipsis etiam uirtutibus?: «Si, cuando hayamos emigrado de esta vida, nos fuera permitido pasar una existencia inmortal en las islas de los bienaventurados, como cuentan las fábulas, ¿qué necesidad habría de elocuencia, al no celebrarse ningún juicio, o incluso de las propias virtudes? $\aleph^{3}$. En ambos textos Cicerón las considera un desiderátum, ficción de los sabios antiguos o producto de «fábulas».

Virgilio (70-19 a. C.) aplica asimismo beatus, además de fortunatus, a lugares míticos. Así, en Aen. 6,637-639, donde se relata la bajada de Eneas a los «infiernos»: His demum exactis, perfecto munere diuae, I deuenere locos laetos et amoena uirecta I fortunatorum nemorum sedesque beatas: «Tras dar fin a estas cosas, hecha la ofrenda a la diosa, / alcanzaron lugares felices y amenos jardines / y de afortunados bosques las sedes dichosas».

De ahí que el comentarista Mario Servio Honorato, a finales del siglo IV, escriba en relación con el verso 638: adludit autem ad insulas fortunatas: nam et sequenti hoc indicat uersu: "por otra parte, alude a las Islas Afortunadas, pues incluso lo indica en el verso siguiente».

Pero la forma más generalizada y, por decirlo así, definitiva, de fortunatorum insulae, está ya en el Trinummus de Plauto (c. 250-184 a. C.), a propósito de un campo adonde deberían ser llevados todos los malos (549-552): Sicut fortunatorum memorant insulas, / quo cuncti qui aetatem egerint caste suam / conueniant; contra istoc detrudi maleficos / aequom uidetur, qui quidem istius sit modi: «A las islas de los afortunados cuentan que / van todos cuantos vivieron con honestidad; / en cambio, justo es más bien echar ahí / a los malvados, si es tal como dices tú».

El hecho de que el sintagma aparezca en un diálogo entre un viejo ciudadano, Filtón, que es quien pronuncia estas palabras, y Estásimo, un esclavo, le da un aire de cotidianidad que sugiere su uso corriente, ya a principios del siglo II a. C., en Roma.

Se trata, pues, de un ideal, por su propio significado de lugar donde van a parar los bienaventurados, quienes lo son en cuanto que quedan libres de cualquier preocupación material.

${ }^{3}$ Este texto es reproducido, indicando incluso el tratado (in Hortensio dialogo), por san Agustín, a principios del siglo v d. C., en De trinitate 14,9. 
Horacio, nacido en el 65 y muerto en el 8 a. C., ejemplifica una especie de dicotomía o transición, si cabe llamarla así, entre la dimensión sobrenatural y la natural de estas islas, a las que aplica el adjetivo diuites, no fortunatae, lo cual, a priori, se presta a las dudas respecto a la identificación.

En Odas 4,8,25-27 habla de Éaco, a quien los poetas, creadores del mito, trasladan a estas islas: Ereptum Stygiis fluctibus Aeacum / uirtus et fauor et lingua potentium / uatum diuitibus consecrat insulis: "A Éaco, arrancado a las aguas Estigias, / su virtud y el favor y voz de influyentes / poetas consagra en las Islas Fecundas ${ }^{4} »$.

El comentarista de la obra horaciana Pomponio Porfirio, ya en el siglo II o III d. C., afirma a propósito del verso 27: Insulas dicit, quas macaron nes[s] us Homerus, Latini fortunatorum insulas appellant: "habla de las islas a las que Homero llama Islas de los Bienaventurados y los latinos Islas Afortunadas». Y los Scholia Pseudacroniana, posteriores al siglo V, explican en relación con el mismo verso: Quas in Oceano constitutas Fortunatas appellant siue insulas beatorum, «a las que, situadas en el Océano, llaman Afortunadas o Islas de los Bienaventurados». Ambos, pues, identifican las dos designaciones.

Pero ya en los Epodos, obra de juventud, Horacio las había descrito no como recompensa en el más allá, sino como lugar para escapar de los malos tiempos que atravesaba Roma, envuelta en una guerra civil. Se trata del tan repetido epodo 16, versos 41-56:

Nos manet Oceanus circumuagus: arua beata petamus, arua diuites et insulas, reddit ubi cererem tellus inarata quotannis et inputata floret usque uinea, germinat et numquam fallentis termes oliuae suamque pulla ficus ornat arborem,

mella caua manant ex ilice, montibus altis leuis crepante lympha desilit pede.

Illic iniussae ueniunt ad mulctra capellae refertque tenta grex amicus ubera, nec uespertinus circumgemit ursus ouile nec intumescit alta uiperis humus; nulla nocent pecori contagia, nullius astri gregem aestuosa torret inpotentia.

Pluraque felices mirabimur, ut neque largis aquosus Eurus arua radat imbribus, pinguia nec siccis urantur semina glaebis, utrumque rege temperante caelitum.

${ }^{4}$ Dada la dificultad de reproducir el ritmo del asclepiadeo menor utilizado aquí por el poeta, me limito a mantener un número constante de doce sílabas, como ya hacía Fernández-Galiano en su edición de la obra del venusino (cf. Fernández-Galiano - Cristóbal, 2000: 66). 
Nos espera el océano, que el mundo rodea: busquemos los ricos campos, las Fecundas Ínsulas:

año tras año te da cereal, sin labrarla, la tierra; florece siempre allí la viña sin podar

y germinan los brotes de olivo, que no fallan nunca; morado, el higo llena a su árbol de color,

mana la miel de las huecas encinas y desde las cumbres el agua cae ligera con sonoro pie.

Van allí por sí mismas a ser ordeñadas las cabras: sus ubres llenas tiende, amiga, aquella grey;

el redil por las tardes el oso no merodea y libre de serpientes el subsuelo está.

No hace daño al ganado contagio ninguno, ni astro ninguno a tu rebaño acosa con su ardor.

Y admiraremos, felices, más cosas: que el húmedo Euro no arrasa el suelo con su lluvia torrencial,

ni las semillas bajo las piedras ardientes se secan ya que de los dioses ambas cosas templa el rey.

Aquí ya no estamos propiamente en el terreno del mito, aun admitiendo que el venusino no describe un lugar determinado, sino su versión de un refugio donde vivir, sin dejar este mundo, a salvo de preocupaciones. Pomponio Porfirio especifica, en su comentario al verso 41: Fortunatas autem insulas significat: «se refiere a las Islas Afortunadas». Y la idea de que el poeta piensa en algo real, por idealizado que esté, llega hasta nuestros días: bastará reproducir aquí la nota de uno de los clásicos editores de Horacio, F. Villeneuve (1927: 226, n. 1): «Horace a pu s’inspirer du projet qu'on avait prété à Sertorius proscrit de s'en aller sur l'Océan à la recherche des îles Fortunées. Nous lisons dans une scolie au v. 425: Ad insulas fortunatas Sallustius in Historia dicit uictum uoluisse ire Sertorius ["Salustio dice en su Historia que Sertorio había querido irse a vivir a las Islas Afortunadas"]».

Este mismo escoliasta hace hincapié en la repetición arua beata, ... arua (versos 41-42), donde Horacio emplea el adjetivo que traduce el genitivo griego. Y a propósito del verso 42 explica el valor semántico de diuites: Idest fecundas, ut Virgilius: Diues opum uariarom ("o sea, fecundas, como Virgilio [Georg. II 468]: "en recursos variados fecunda" ), referido a secura quies et nescia fallere uita, "apacible quietud y vida exenta de engaños», que disfrutan, felices, los labradores. Incluso en el referido al verso 43 también aparecen las islas: Hoc loco describit situm amoenum et felicitatem Fortunatarum Insularum, quae sunt in Oceano, «en este pasaje describe un lugar placentero y la felicidad de las Islas Afortunadas, que están en el Océano».

\footnotetext{
${ }^{5}$ Los Scholia Pseudacroniana mencionados antes; el verso de referencia es el 41, no el 42.
}

${ }^{6}$ El texto del escolio dice literalmente: Oceanus] In quo sunt Insulae Fortunatae ad quas Sallustius... 
Así pues, entre los latinos el sustantivo fortunatus, utilizado para designar a los seres sobrenaturales premiados tras la muerte con un retiro paradisíaco, se transforma en calificativo de las islas mismas, que pasan a ser ellas las privilegiadas. A partir de ahí, quedará como designación geográfica específica durante siglos, sin que desaparezca, ni mucho menos, la vinculación de estas islas con el mito.

Por desgracia, lo poco que nos ha llegado de la Historia de Salustio (86-35 a. C.), y en concreto respecto a la relación de Quinto Sertorio, unos decenios más joven que él (122-73 o 72 a. C.), con las Islas Afortunadas permite afirmar que este asunto fue tratado en la obra y poco más $(1,99-102)$ : Cum Sertorius neque erumpere tam leui copia nanibus... Quas duas insulas propinquas inter se et decem <milia> stadium procul a Gadibus sitas constabat suopte ingenio alimenta mortalibus gignere. Traditur fugam in Oceani longinqua agitauisse: "Sertorio no lanzarse con tan escasa cantidad de embarcaciones.... Constaba que esas dos islas, cercanas entre sí y situadas a diez mil estadios de distancia de Gades, generaban de forma espontánea alimentos para los mortales. Se dice que había pensado huir a zonas remotas del Océano».

Este texto deja claro que mediado el siglo I a. C. se conocía en Roma la existencia real de unas islas paradisíacas y su ubicación respecto a Gades.

Como es sabido, la información más completa llegada hasta nosotros sobre el asunto la ofrece Plutarco (c. 50-c.125 d. C.) en el tomo IV de sus Vidas paralelas (Sertorius 8,3-9,1), tras informar de que unos marineros gaditanos le habían hablado a Sertorio de dos islas del Atlántico, llamadas Maká $\rho \omega v$, «De los bienaventurados». Aun cuando el texto es de cierta extensión, no vendrá mal reproducir, una vez más, la parte que atañe a lo que estamos comentando:

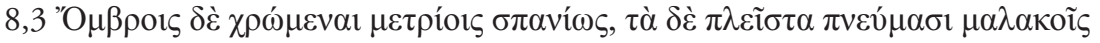

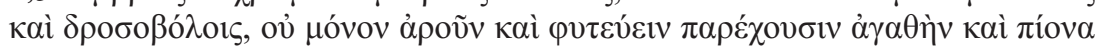

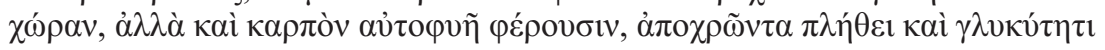

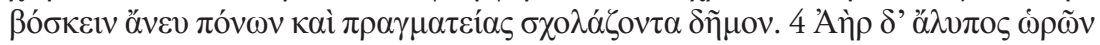

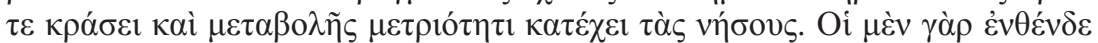

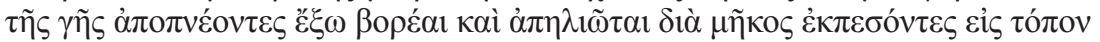

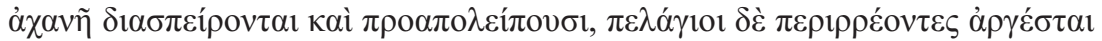

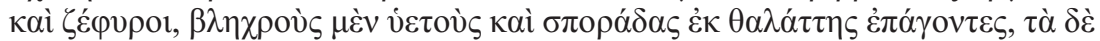

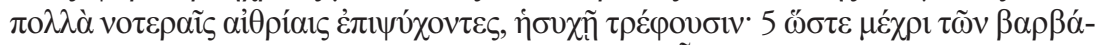

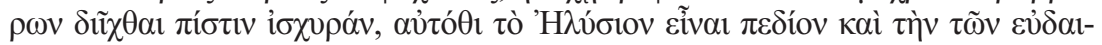

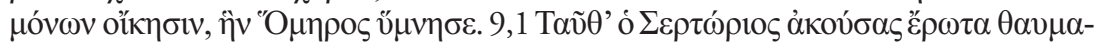

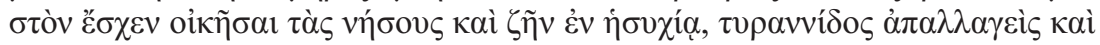
$\pi \mathrm{o} \lambda \dot{\varepsilon} \mu \omega v \dot{\alpha} \pi \alpha v ́ \sigma \tau \omega v$.

Disfrutan de lluvias moderadas y ocasionales, y casi siempre de vientos suaves y cargados de rocío, que no solo proporcionan una tierra buena y crasa, adecuada para sembrar o plantar, sino también producen espontáneamente frutos abundantes y agradables para alimentar, sin fatiga ni esfuerzo, a un pueblo ocioso. Un clima bonancible por la equiparación de las estaciones y la moderación de sus ciclos envuelve las islas. Pues los vientos del norte y del este, que soplan desde la tierra, difundiéndose por la distancia en un amplio espacio, se disipan y pierden previamente su fuerza; y los vientos marinos, de poniente y mediodía, que fluyen en torno, llevando desde el mar lluvias moderadas y dispersas, e impulsando la mayoría de las veces vapores 
húmedos, aportan nutrientes poco a poco. En consecuencia, incluso ha penetrado entre los extranjeros la creencia firme de que allí mismo se sitúan los Campos Elíseos y la morada de los bienaventurados, que cantó Homero. Sertorio, al oír estas cosas, concibió el extraño deseo de habitar en esas islas y vivir en paz, libre de la tiranía y de las guerras constantes.

El pasaje desarrolla, con una detenida descripción del clima y sus efectos, lo dicho por Homero, en el siglo VIII a. C., a propósito de los Campos Elíseos; la conclusión resulta obvia y justifica el deseo del atribulado Sertorio. Veamos los versos de la Odisea, donde el poeta narra la profecía del destino que le espera a Menelao $(4,563-568)$ :

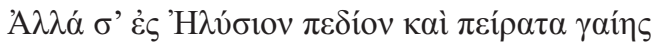

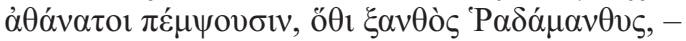

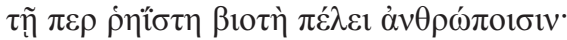

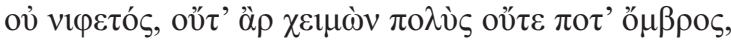

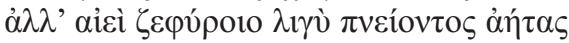

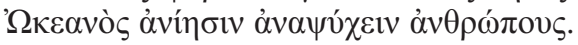

Mas a ti te enviarán a los campos elíseos los dioses, donde el rubio Radamante, al confín de la tierra; se hace fácil allí la vida a los hombres en todo: nieve no hay, ni invierno intenso, ni lluvia excesiva, sino que siempre un poniente suave que sopla armonioso manda el océano a fin de dar solaz a los hombres.

Homero coincide con Hesíodo al situar los campos elíseos en el confín de la tierra, protegidos por el Océano (aun cuando no indique que son islas) y también al asignarles una naturaleza que proporciona a los hombres una vida sin preocupaciones; la diferencia está en los recursos naturales especificados: para Hesíodo el suelo fecundo, para Homero el clima benigno; veremos cómo en lo sucesivo hay quien opta por uno u otro de ellos y quien opta por ambos.

Lucio Annio Floro, el historiador originario de África, que vivió en el último tercio del siglo I y murió a mediados del II d. C., se refiere asimismo a la vinculación de Sertorio con las Islas Afortunadas. En su Epitome bellorum omnium annorum DCC, 2,10, dice de él: uir summae quidem sed calamitosae uirtutis malis suis maria terrasque permiscuit; et iam Africae, iam Balearibus insulis fortunam expertus usque in Oceanum Fortunatasque insulas penetrauit consiliis: "hombre ciertamente de un valor muy grande, pero calamitoso, perturbó mares y tierras con sus propias desgracias. Y tras probar fortuna ora en África, ora en las Islas Baleares, penetró en sus planes hasta el Océano y las Islas Afortunadas».

Volviendo a Horacio, no cabe descartar que conociera los datos manejados posteriormente por Plutarco; de hecho, como hemos visto, ni siquiera conservamos el texto íntegro de la Historia escrita por Salustio, y el fragmento llegado hasta nosotros coincide en la noticia de las dos islas y el deseo de Sertorio. Su exuberancia de poeta joven le induciría a pintarlas con detalles propios de su entorno, incluidos los animales, totalmente ausentes de los textos precedentes. 
La identificación del Elíseo con las Islas Afortunadas está señalada expresamente en relación con Salustio por Servio, el ya mencionado comentarista de Virgilio, a propósito de las palabras de Anquises a su hijo Eneas, en Aen. 5,734-735: amoena piorum / concilia elysiumque colo «las amenas reuniones de los piadosos y el Elíseo frecuento"; ahí leemos: Secundum philosophos elysium est insulae fortunatae, quas ait Sallustius inclitas esse Homeri carminibus, quarum descriptionem Porphyrius commentator dicit esse sublatam: «Según los filósofos, el Elíseo es las Islas Afortunadas, las cuales señala Salustio que son destacadas en los poemas de Homero, cuya descripción dice el comentarista Porfirio que ha sido eliminada».

También a comienzos del siglo V, san Jerónimo (c. 347-420 d. C.), en su escrito Contra Vigilantium 6, menciona el Elíseo junto a las Islas Afortunadas cuando echa en cara a su oponente la afirmación irónica de que las almas de los apóstoles y los mártires senatoriae uidelicet dignitatis sunt. Et non inter homicidas teterrimo carcere, sed in libera honestaque custodia in Fortunatorum Insulis et in Campis Elysiis recluduntur. «son, al parecer, de dignidad senatorial. Y no se les recluye entre los homicidas dentro de una lobreguísima cárcel, sino en una custodia libre y honrosa en las Islas Afortunadas y en los Campos Elíseos».

Respecto a la nomenclatura, se singulariza Arnobio, de Sicca Veneria, precisamente una ciudad del África proconsular (hoy Le Kef, al noroeste de Túnez) y, por lo tanto, próximo geográficamente a aquello de lo que habla, dado que utiliza por primera (y única) vez en muchos siglos, el plural Canariae insulae ${ }^{7}$. Lo hace en Aduersus nationes, escrito hacia el año 300 d. C., 6,5,2: Constituamus enim noscendae rei causa templum numinis alicuius esse apud Canarias insulas, eiusdem apud ultimam Thylem, eiusdem apud Seras esse, apud furuos Garamantas et si qui sunt alii quos ab sui notitia maria montes siluae et quadrini disterminant cardines: "Pues establezcamos, para conocer el asunto, que existe un templo de alguna divinidad en las Islas Canarias, de esa misma en la extrema Tule, de esa misma en el país de los Seres, o en el país de los negros Garamantes, y si existen algunos otros de cuyo conocimiento se separan los mares, los montes, los bosques y los cuatro puntos cardinales».

Como se ve, Arnobio marca los límites del mundo entonces conocido, en dirección oeste-norte-este-sur, con las Islas Canarias para el extremo occidental, la legendaria isla de Tule para el septentrional, el pueblo de los Seres, en la India, para el oriental, y el de los Garamantes, al sur de África, para el meridional ${ }^{8}$. Sabido es que probablemente desde el Orbis Terrarum o Mapa de Agripa, muerto en el año 12 a. C.?, y sin duda desde Marino de Tiro y Ptolomeo, el meridiano cero, que marcaba el punto más alejado hacia occidente, estaba situado en las islas Canarias, y así se mantuvo hasta que en 1884 pasó a Greenwich. Lo que solo puede ser objeto de conjetura es

${ }^{7}$ A este plural le dedica específicamente M. Martínez Hernández uno de sus trabajos (1993).

${ }^{8}$ Virgilio, por ejemplo, califica a estos de extremi (ecl. 8,44), y, siguiendo en su estela, Silio Itálico de remoti $(16,630)$.

${ }^{9}$ Puede verse al respecto Santana - Arcos (2007); Santana (2015). 
ese plural Islas Canarias, que extiende a otra u otras la designación específica de una de ellas, ya de por sí sometida a no pocas hipótesis.

Pero los autores latinos desconocen este texto, o, por lo menos, la designación que utiliza, y siguen llamando a las Canarias Fortunatae / Fortunatorum insulae, con ese mismo orden de sus elementos o con el inverso.

La situación geográfica con respecto a la rosa de los vientos estaba ya en un texto anterior, de Lucio Ampelio, quien probablemente escribió su breve Liber memorialis a finales del siglo II d. C. Allí distribuye las islas en distinto orden, oesteeste-norte-sur, y coloca a las Afortunadas en el extremo meridional del mundo, no en el occidental; solo coincide con Arnobio en la posición de Tule (6,13): Clarissimae insulae: [...] in Oceano: ad orientem Taprobane, ad occidentem Brittanni<a $>$, ad septentrionem Thyle, ad meridiem Insulae Fortunatae: «Islas más destacadas ... en el Océano: al oriente Taprobane ${ }^{10}$, al occidente Britania, al norte Tule, al sur las Islas Afortunadas».

Hablando de confines, asimismo el hispano Paulo Orosio, que estuvo en África refugiado junto a san Agustín, escribió a principios del siglo v d. C. sus Historiae aduersus paganos, donde informa de que (1,2,10-11): Termini Africae ad occidentem idem sunt qui et Europae, id est fauces Gaditani freti. 11 Vltimus autem finis eius est mons Athlans et insulae quas Fortunatas uocant: "Los límites de África hacia occidente son los mismos que los de Europa, esto es, la embocadura del Golfo Gaditano. Por otra parte, su último confín es el monte Atlas y las islas que llaman Afortunadas»; texto que, con ligeras variantes ${ }^{11}$, reproduce un cosmógrafo anónimo, probablemente del siglo VI d. C. $(2,3)$, tras citar a las Afortunadas entre las islas del océano meridional $(1,41)$.

También Sulpicio Severo (c. 360-c. 425), cuando en los Dialogorum libri 1,26,2, quiere dejar clara la universalidad de un aserto, escribe, colocando a las Canarias en el confín del mundo: Hoc Aegyptus fatetur, hoc Syria, hoc Aethiops conperit, hoc Indus audiuit, hoc Parthus et Persa nouerunt, nec ignorat Armenia, Bosporus exclusa cognouit, et postremo si quis aut Fortunatas insulas aut glacialem frequentat oceanum: «Esto lo reconoce Egipto, esto Siria, esto lo comprende el etíope, esto lo ha oído el indio, esto lo han sabido el parto y el persa, y no lo ignora Armenia, lo ha conocido el Bósforo lejano y, en fin, si alguien frecuenta las Islas Afortunadas o el glacial océano".

A mediados del siglo VI d. C., Jordanes menciona la ubicación de las islas a la altura de Cádiz, si bien su conocimiento del archipiélago es de una notable confusión; en su De origine actibusque Getarum afirma (7): Habet in parte occidua idem Oceanus aliquantas insulas et pene cunctis ob frequentiam euntium et redeuntium notas. Et sunt iuxta fretum Gaditanum haut procul una Beata et alia quae dicitur Fortunata: «Tiene el mismo Océano en la parte occidental unas cuantas islas, conocidas casi

\footnotetext{
${ }^{10}$ La actual Sri Lanka, antigua Ceilán, en el Golfo de Bengala.

${ }^{11}$ Arranca con Terminus Africae ipse est qui.
} 
por todos debido a la frecuencia de quienes van y vienen. Y están a la altura del Golfo Gaditano, no lejos una, Bienaventurada, de otra a la que llaman Afortunada».

$Y$, si bien ya se conoce al menos su existencia real, no son pocos los que siguen refiriéndose a ellas como un lugar de descanso post mortem para los bienaventurados.

Así, Claudio Mamertino, en la Gratiarum actio de Consulatu suo Iuliano imperatori, pronunciada a comienzos del año 362 , apunta $(23,1)^{12}$ : Habitari ab iustis uiris in Oceano terras ferunt quas Fortunatorum insulas uocant, quod per eas non arato solo frumenta nascuntur, fortuitis uitibus iuga collium uestiuntur, sponte pomis arbor grauatur, ad herbarum uicem olus uulgo est. «Se dice que los justos habitan unas tierras en el océano a las que llaman Islas de los Afortunados, porque a lo largo de ellas nacen los cereales del suelo sin ararlo, las vertientes de las colinas se visten de viñas imprevistas, el árbol se carga espontáneamente de frutos y de ordinario hay hortalizas en lugar de hierbas».

Este pasaje está a medio camino, formal, entre las Beatorum insulae y las Fortunatae insulae, con su interpretación como lugar donde viven los «justos», o sea, los «bienaventurados» para los cristianos, descrito con detalles tomados de la tradición literaria precedente, que ya hemos comentado.

San Isidoro de Sevilla, el gran recopilador que escribió a lo largo del primer tercio del siglo VII sus Etimologías, tan difundidas en toda la Edad Media, parte de la existencia real de las islas y, basándose en ella, deduce su interpretación mítica como lugar de los bienaventurados; detrás está Plinio, una de sus fuentes habituales, pero también una frase de Claudio Mamertino, quien, como acabamos de ver, escribe Fortunatorum insulae, lo cual induce a modificar formalmente el vocablo inicial, transmitido por los códices, dando al sintagma coherencia desde el punto de vista gramatical. El texto está en 14,6,8:

Fortunatarum insulae uocabulo suo significant omnia ferre bona, quasi felices et beatae fructuum ubertate. Sua enim aptae natura pretiosarum poma siluarum parturiunt; fortuitis nitibus inga collium uestiuntur; ad herbarum nicem messis et holus unlgo est. Vnde gentilium error et saecularium carmina poetarum propter soli fecunditatem easdem esse Paradisum putauerunt. Sitae sunt autem in Oceano contra laeuam Mauretaniae, occiduo proximae, et inter se interiecto mari discretae.

Las Islas de los Afortunados significan con su propio nombre que producen todos los bienes, algo así como felices y bienaventuradas por la abundancia de frutos. En efecto, capaces por su propia naturaleza, generan las frutas de bosques exquisitos, visten las vertientes de las colinas con viñas imprevistas, de ordinario hay mieses y hortalizas en lugar de hierbas. A partir de ahí la equivocación de los gentiles y los versos de los poetas paganos pensaron que ellas eran el Paraíso a causa de la fecundidad del suelo. Por lo demás, están situadas en el Océano frente a la izquierda de Mauritania, cercanas al extremo occidental y separadas entre sí por la interposición del mar.

${ }^{12}$ Tomo el texto de Mynors (1964). 
En cuanto a quienes se centran en la geografía, dejando aparte los que para nosotros solo son informadores probables, como Hannón y su Periplo, más Estacio Seboso y Juba II, fuentes de Plinio, nos ha llegado un texto de Pomponio Mela, natural de Tingentera, en la bahía de Algeciras, una zona geográfica muy vinculada con los territorios africanos (de hecho, cuando habla de su ciudad natal puntualiza: quam transuecti ex Africa Phoenices habitant. «la habitan púnicos trasladados desde Africa $\left.{ }^{13}\right)$. Su tratado De chorographia, escrito muy probablemente entre los años 41 y $44 \mathrm{~d}$. C., es el primero de este tipo que conocemos en la literatura latina. Allí se lee lo siguiente (3,100-104): Exustis insulae adpositae sunt quas Hesperidas tenuisse memoratur. [...Athlas...] Contra Fortunatae insulae abundant sua sponte genitis, et subinde aliis super alia innascentibus nibil sollicitos alunt, beatius quam aliae urbes excultae. Vna singulari duorum fontium ingenio maxime insignis: alterum qui gustauere risu soluuntur in mortem; ita adfectis remedium est ex altero bibere: «Al costado de la zona tórrida están las islas que, cuentan, fueron habitadas por las Hespérides. Enfrente (del Atlas), las Islas Afortunadas abundan en frutos que surgen espontáneamente $y$, naciendo sin cesar unos tras otros, alimentan a quienes de nada se ocupan, con un bienestar mayor que el de otras ciudades bien cultivadas. Hay una sumamente notable debido a la naturaleza singular de dos fuentes: los que han saboreado una se debilitan por la risa hasta la muerte; el remedio para los afectados de este mal es beber de la otra».

Aparte de separar las Hespérides de las Afortunadas, Mela aporta un detalle más bien poco creíble, los efectos de esas dos fuentes, si bien, como veremos más adelante, otros textos certifican su existencia y sus propiedades contrapuestas, pero de índole más razonable (y comprobable). En cuanto al texto, es de notar que A. Silberman (1988: 322) duda de la lectura aliae urbes excultae, aduciendo por una parte que las Islas Afortunadas nunca han sido urbes y por otra que excultae supone un cuidadoso cultivo que no encaja en el abundant sua sponte genitis, propone aliubi en vez de urbes, o sea, «un bienestar mayor que el de otras (islas) cuidadosamente cultivadas en otros lugares». Baste, por ahora al menos, señalar estas reservas, que comparte con otros autores.

Todavía el geógrafo Agatárquides de Gnido (c. 190-105 a. C.), en su obra

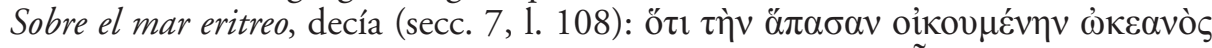

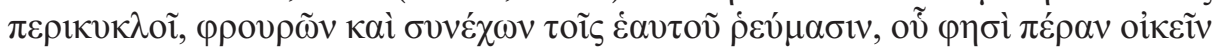

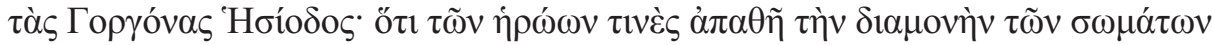

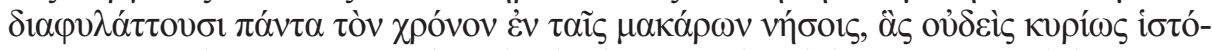

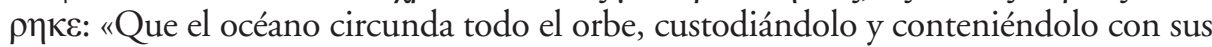
corrientes, donde dice Hesíodo que habitan las Gorgonas; y que algunos de los héroes se mantienen incólumes, sin sufrimiento, para siempre en las islas de los bienaventurados, de las cuales ningún historiador ha dicho nada con certeza».

${ }^{13}$ Efectivamente Tingentera "parece relacionado con Tingis (Tánger, Marruecos)» (Correa Rodríguez, 2016: 468). 
Pero no mucho después, Estrabón, de Amara, en la península de Anatolia (c. 74 a. C.-17 d. C.), escribió diecisiete libros, titulados Geográficos, donde enseña

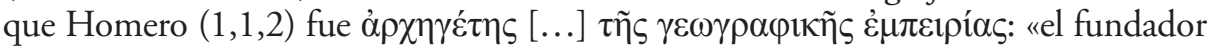
del estudio empírico de la geografía» $(1,1,4-5)$,

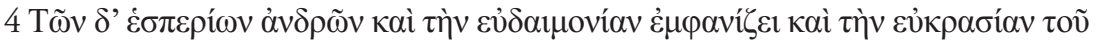

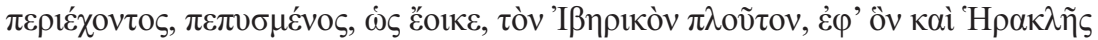

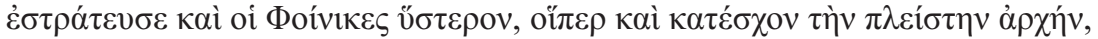

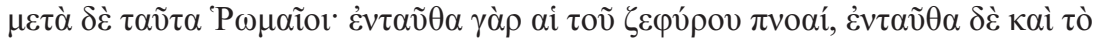

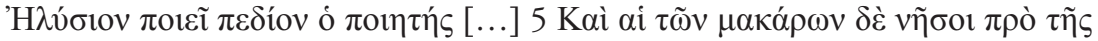

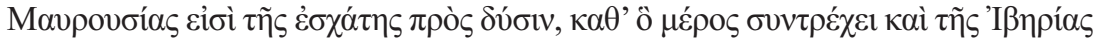

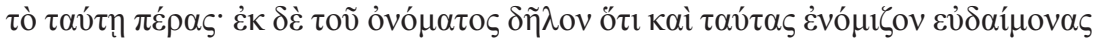

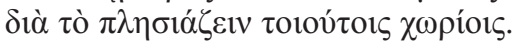

Muestra la felicidad de las gentes de occidente, así como el buen clima de su entorno, estando informado, según parece, de la riqueza de Iberia, por la que luchó Heracles y más tarde los fenicios, los cuales incluso la dominaron en su mayor parte, y con posterioridad los romanos; pues allí sopla el céfiro, y allí el poeta pone el campo elíseo. ... Igualmente las Islas de los Bienaventurados están ante al extremo de Mauritania, hacia poniente, por la parte que coincide también con el límite correspondiente de Iberia, y a partir de su nombre es evidente que se las consideraba felices por estar cerca de lugares semejantes».

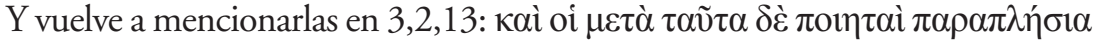

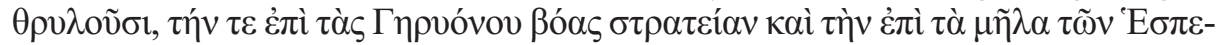

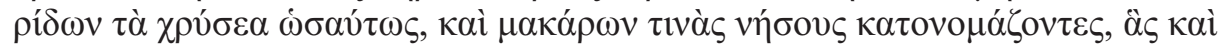

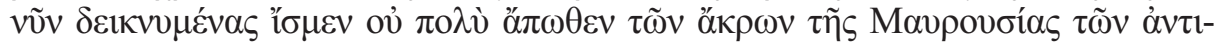

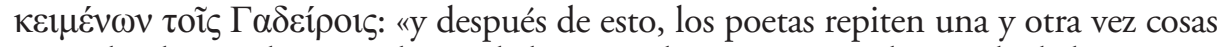
parecidas: la expedición en busca de las vacas de Gerión e igualmente la de las manzanas de oro de las Hespérides, llamando incluso a algunas islas "de los Bienaventurados", las que ahora vemos que se divisan no muy lejos de los promontorios de Mauritania situados frente a Gádira».

Estos textos, que reflejan el paso del mito, cantado por los poetas, a la realidad en relación con las Islas de los Afortunados, evidencian que para el autor el nombre se debe a su situación geográfica en occidente, donde el clima es bonancible porque soplan los céfiros, y que tiene noticia del lugar en que se encuentran realmente, en la vertical de la bahía de Cádiz.

Pero el pasaje más importante para conocer lo que sabían los antiguos acerca de esta zona geográfica es el tantas veces repetido de la Naturalis historia (6,201-205) escrita por Gayo ${ }^{14}$ Plinio Segundo (23-79 d. C.):

${ }^{14}$ Ya que estamos «en plan filológico», bueno será recordar a quienes lo saben, e informar a quienes no, que el praenomen Caius de Plinio, de César, de Salustio, de Solino y de tantos otros, debe ser traducido por «Gayo»: lo deja bien claro, entre otros, nuestro Quintiliano, cuando dice (inst. 1,7,28) 
201 Vltra has etiamnum duae Hesperidum insulae narrantur, adeoque omnia circa hoc incerta sunt, ut Statius Sebosus a Gorgonum insulis praenanigatione Atlantis dierum XL ad Hesperidum insulas cursum prodiderit, ab his ad Hesperu Ceras unius. Nec Mauretaniae insularum certior fama est. Paucas modo constat esse ex aduerso Autolol $<u>m$ a Iuba repertas, in quibus Gaetulicam purpuram tinguere instituerat.

202 Sunt qui ultra eas Fortunatas putent esse quasdamque alias, quo <in> numero idem Sebosus etiam spatia conplexus Iunoniam abesse a Gadibus $<D C C L>p$. tradit, ab ea tantundem ad occasum uersus Plunialiam Caprariamque; in Pluuialia non esse aquam nisi ex imbri. Ab iis $<C C L>$ Fortunatas contra laeuam Mauretaniae in VIII horam solis; uocari Inuallem a conuexitate et Planasiam a specie, Inuallis circuitu $<C C C>$ p.; arborum ibi proceritatem ad CXL pedes adulescere. 203 Iuba de Fortunatis ita inquisiuit: sub meridiem quoque positas esse prope occasum, a Purpurariis $\langle D C X X V\rangle$ p., sic ut $\langle C C L\rangle$ supra occasum nauigetur, dein per $<C C C L X X V>$ ortus petatur. Primam uocari Ombrion, nullis aedificiorum uestigiis; habere in montibus stagnum, arbores similes ferulae, ex quibus aqua exprimatur, e nigris amara, ex candidioribus potui iucunda. 204 Alteram insulam Iunoniam appellari; in ea aediculam esse tantum lapide exstructam. Ab ea in uicino eodem nomine minorem, deinde Caprariam, lacertis grandibus refertam. In conspectu earum esse Ninguariam, quae hoc nomen acceperit a perpetua niue, nebulosam. 205 Proximam ei Canariam uocari a multitudine canum ingentis magnitudinis - ex quibus perducti sunt Iubae duo-; appare<re> ibi uestigia aedificiorum. Cum omnes autem copia pomorum et auium omnis generis abundent, hanc et palmetis caryotas ferentibus ac nuce pinea abundare; esse copiam et mellis, papyrum quoque et siluros in amnibus gigni. Infestari eas beluis, quae expellantur adsidue, putrescentibus.

Todavía más allá de estas ${ }^{15}$, se habla de las dos islas de las Hespérides y, hasta tal punto es incierto todo lo relacionado con ello, que Estacio Seboso señaló una distancia, en navegación costera por la zona del Atlas, desde las islas de las Gorgonas hasta las islas de las Hespérides, de cuarenta días y desde estas hasta el Hesperu Ceras de uno solo. Y no es mucho más fiable lo que se dice respecto a las islas de Mauritania. Solo consta que hay unas pocas descubiertas por Juba frente a las Autóloles, en las cuales había dispuesto teñir púrpura getúlica.

Hay quienes piensan que más allá de estas están las Afortunadas y algunas otras, en cuyo número el mismo Seboso, tras completar las distancias, relata que Junonia dista de Gades 750.000 pasos, y Pluvialia y Capraria otro tanto desde esta en dirección al ocaso; que en Pluvialia no hay agua más que la de lluvia. A 250.000 pasos de estas, las Afortunadas frente a la izquierda de Mauritania en la octava hora del sol ${ }^{16}$; que se las llama Invale, por su concavidad, y Planasia por su aspecto, Invale con un contorno de 300.000 pasos; que allí la altura de los árboles alcanza los 140 pies.

'Gaius' C littera significatur. "Gaius se indica con la letra $C$.». Efectivamente, la $C$ corresponde a la letra gamma del alfabeto griego del que se tomó el latino; y la notación de los praenomina remonta, obviamente, a los primeros tiempos, cuando todavía ese signo, con la adición de un trazo, no había pasado a $G$.

${ }^{15}$ Se refiere a las Gorgades o Gorgonas.

${ }^{16}$ En la rosa de los vientos marca la dirección oeste-noroeste. 
Juba indagó acerca de las Afortunadas lo siguiente: están situadas bajo mediodía cerca del ocaso, a 625.000 pasos de las Purpurarias, de forma que se debe navegar 250.000 pasos sobre el ocaso, luego alcanzar el orto a lo largo de 375.000. Que a la primera se le llama Ombrios, sin vestigio alguno de edificios: que tiene en los montes una laguna y árboles semejantes a la cañaheja, de los cuales se exprime agua, de los negros amarga, de los más blancos agradable para beber. Que la otra isla es llamada Junonia; en ella hay un templete construido solo de piedra; vecina a ella otra menor del mismo nombre; luego Capraria, repleta de grandes lagartos. Que a la vista de estas está Ninguaria, la cual habría recibido este nombre por su nieve perpetua, cubierta de nubes. Que, próxima a ella, Canaria es llamada así por la multitud de canes de ingente tamaño, dos de los cuales fueron llevados a Juba; que allí aparecen vestigios de edificios. Mientras todas abundan en cantidad de frutales y aves de toda clase, esta abunda también en palmeras productoras de dátiles, y en piñas; que también hay cantidad de miel, y nacen además papiro y siluros en los ríos. Que están infestadas de animales en putrefacción, que son expulsados allí regularmente.

Como este texto ha sido comentado por multitud de investigadores de diversos campos, me limitaré a insistir sobre algunos aspectos formales. Para empezar, Plinio indica sus dos fuentes: el geógrafo Estacio Seboso, que cabe situar cronológicamente en un arco que va desde los comienzos del siglo I a. C. hasta la época del propio Plinio, y Juba II, rey de Mauritania ${ }^{17}$ (52 a. C.-23 d. C.). Plinio, además de explicitar la inseguridad de las noticias que ofrece, prodiga la voz pasiva, menos categórica, por decirlo así, que la activa. Reproduce las distancias que le facilitan sus fuentes, y son al menos admisibles (Santana - Arcos - Atoche - Martín, 2002: 189, 329...), recoge información sobre el poblamiento (Ombrios sin vestigios, Canaria con restos de haber estado habitada) y ofrece nombres y datos que solo permiten identificar con cierta seguridad dos de las islas: Canaria con Gran Canaria y Ninguaria con Tenerife ${ }^{18}$. Las nomenclaturas se basan en detalles visibles o perceptibles, generales como el aspecto (Invale, de la que aporta incluso las dimensiones; Planasia, designación esta que el propio Plinio aplica también a una isla del mar Tirreno, hoy Panarea, conocida por otros autores como Varrón o Tácito ${ }^{19}$, justificándola con las mismas palabras ${ }^{20}$, lo cual muestra el carácter descriptivo de estas designaciones,), y el clima (Ninguaria, Ombrion/Pluvialia), o bien específicas: Junonia, por el pequeño templo allí visible; Canaria, por los perros, con el detalle de su gran tamaño, que indujo a llevar un par de ejemplares a Juba: por cierto, este hecho, aparte de otras consideraciones, me hace dudar de que la isla se llame así por el pueblo de los Canarii, que Plinio, y nadie más, al menos en la Antigüedad, menciona no muy lejos (nat. 5,15), y sin embargo no lo

${ }^{17}$ Para un amplio estudio de este personaje y su obra remito a la tesis doctoral de A. Ma García García (2007).

${ }^{18}$ Para los nombres de las islas remito a Martínez Hernández (1994a).

${ }^{19}$ VARro, rust. 3,62; TAC. ann. 1,3,19.

${ }^{20}$ Cf. nat, 3,80,7 Plana $<$ s>ia a specie dicta. 
vincula en absoluto con el nombre de la isla; por otro lado, resulta difícil aceptar que, basándose expresamente en el informe de Juba, se invente lo de los dos ejemplares que le llevaron al rey. Es de notar también que solo en el caso de Capraria omite la relación expresa (dicitur, nuncupatur...) del nombre con el detalle de la presencia de animales concretos, aquí lagartos, lo cual sugiere que él mismo no tenía nada clara la posible vinculación del nombre que leía en su fuente, desde luego en tal caso deformado, con lo visto en esa isla; de hecho, se han sugerido posibles variantes, algunas de las cuales veremos más adelante.

Debo añadir una nota filológica: no me parece adecuado optar por la lectura Cum omnes autem copiae pomorum et auium omnis generis abundent (cf. García García, 2009: 158, n. 37, o García García - Tejera Gaspar, 2014: 162, n. 6): aparte de cambiar el sentido del texto, porque omnes se refiere a las islas, el verbo rige ablativo, por lo que encaja perfectamente copia, sintagma que usan más de una vez los clásicos, entre otros César (vgr. ciu. 1,49,1 omnium rerum abundabat copia), Cicerón (vgr. Font. 43 eorum hominum copia populum Romanum abundare), Tito Livio (vgr. 29,25,12 abundans omnium copia rerum) o el propio Plinio (vgr. nat. 26,18 omnium rerum copia abundarent); además, el plural de copia tiene sobre todo un uso militar, con el significado general de 'tropas'.

Más necesario veo hacer algunas puntualizaciones respecto al artículo de García-Talavera (2006), calificado por él mismo de polémico, dado que señala como «malas traducciones» algunas de las aquí ofrecidas, forzando los textos para encajarlos en sus, por demás interesantes, interpretaciones, cuyo comentario global superaría mis competencias. Así, en la pág. 74 afirma: «Y luego pasaron a Capraria (Lanzarote), donde encontraron que estaba, según relata: lacertis grandibus refertam, cuya traducción debería ser: "plagada de lagartos o con grandes concentraciones de lagartos" y no, como se ha venido repitiendo por la mayoría de autores: "repleta de grandes lagartos". Esta es otra repetitiva confusión, por mala traducción, que ha llevado a gran parte de esos investigadores a trasladar Capraria a El Hierro».

En primer lugar, refertus significa 'repleto' (por lo que puede valer «con grandes concentraciones»); además, es de notar que 'plagado' implica un matiz que no tiene el original latino: la Academia, en efecto, define el verbo 'plagar' como (la cursiva, obviamente, es mía) «Llenar o cubrir a alguien o algo de una cosa generalmente nociva o no convenienter. En todo caso, de admitir la interpretación propuesta, sobraría el adjetivo grandibus aplicado a lacertis, que, por lo demás, califica preferentemente al cuerpo; valgan aquí las palabras de san Isidoro de Sevilla, quien, partiendo de fuentes previas, distingue (diff:: 1,277$)$ inter grande et maximum: grande ad corpus pertinet, maximum ad animum: «entre grande y maximum. Grande se relaciona con el cuerpo, maximum con el espíritu»; y más adelante insiste (1,362): Inter magnum et grande. Magnum ad animum referimus, grande ad corpus. «Entre magnum y grande. Referimos magnum al espíritu, grande al cuerpo».

Algo más adelante, en la pág. 79, García-Talavera escribe:

Lo que viene a continuación se refiere a Ninguaria (Fuerteventura) y no a Canaria, como repetitivamente se ha ido copiando e interpretando por malas traducciones del texto original. Después de un punto y coma, dice: «..., que en ella (Ninguaria) 
aparecen vestigios de edificaciones (...); que si bien en todas abundan en cantidad los frutos y aves de toda clase, ésta asimismo abunda en palmeras datileras y en coníferas.. Los «frutos» que comenta Plinio, no son frutas como normalmente imaginamos, sino productos o recursos naturales, fundamentalmente marinos.

Plinio dice copia pomorum, y pomum significa 'fruta' ${ }^{21} \mathrm{o}$ 'frutal', pero, que yo sepa, no tuvo nunca, por lo menos en el periodo que abarcan los textos que aquí tratamos, ese sentido general de «recursos naturales», y todavía menos «fundamentalmente marinos» que, como es obvio, pertenecen al reino animal, no al vegetal.

En el siglo siguiente a Plinio, probablemente entre el 100 y el 178 d. C., vivió Claudio Ptolomeo, natural de Ptolemaida, en Egipto. A él se le debe una Guía geográfica destinada a alcanzar muy notable difusión, en cuyo libro IV $(6,34)$ enumera las

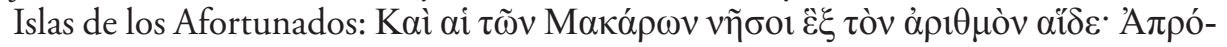

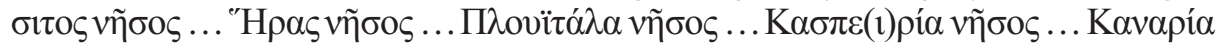

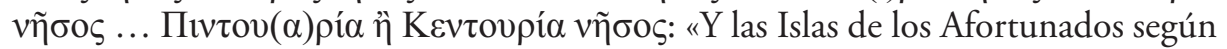
el cálculo, son estas, isla Aprósitos, isla de Hera, isla Pluitala, isla Casperia, isla Canaria, isla Pinturia o Centuria». No es difícil identificar la correspondencia con los nombres

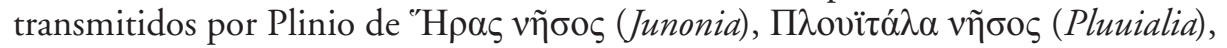

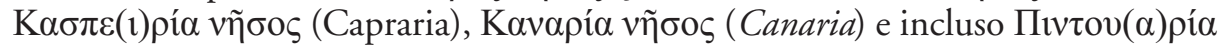

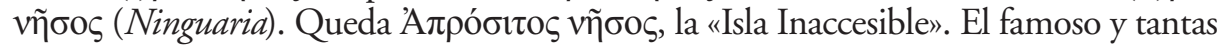
veces reproducido mapa que se basa en este texto, generalmente atribuido a Agathodemon (siglo IV d. C.), las coloca, de norte a sur, por ese orden, en una línea paralela a la costa inclinada levemente hacia occidente.

Siguen el texto de Plinio los Collectanea rerum memorabilium escritos por Gayo Julio Solino, que vivió en el siglo III o quizá en el IV d. C. (56,13-19):

13 Vltra Gorgadas Hesperidum insulae, sicut Sebosus adfirmat, dierum quadraginta nauigatione in intimos maris sinus recesserunt. 14 Fortunatas insulas certe contra laeuam Mauretaniae accepimus iacere, quas Iuba sub meridie quidem sitas, sed proximas occasui dicit. 15 De harum nominibus expectari magnum <non> miror, sed infra famam uocabuli res est. In prima earum, cui nomen est Embrion, aedificia nec sunt nec fuerunt. Iuga montium stagnis madescunt. Ferulae surgunt ad arboris magnitudinem; earum quae nigrae sunt, expressae liquorem reddunt amarissimum, quae candidae, aquas reuomunt etiam potui accommodatas. 16 Alteram insulam Iunoniam appellari ferunt, in qua pauxilla aedes ignobiliter ad culmen fastigata. Tertia huic proximat eodem nomine, nuda omnia. Quarto loco Capraria appellatur, enormibus lacertis plus quam referta. 17 Sequitur Niuaria aere nebuloso et coacto ac propterea semper niualis. Deinde Canaria repleta canibus forma eminentissimis, unde etiam duo exhibiti sunt Iubae regi. 18 In ea aedificiorum durant uestigia. Auium magna copia, nemora pomifera, palmeta caryotas feritantia, multa nux pinea, larga mellatio, amnes siluris piscibus abundantes. 19

${ }^{21}$ De hecho, persiste en el español "poma» que, según la Academia, significa genéricamente «fruta de árbol», y más específicamente «manzana». 
Perbibent etiam expui in eam undoso mari beluas; deinde cum monstra illa putredine tabefacta sunt, omnia illic infici taetro odore; ideoque non penitus ad nuncupationem sui congruere insularum qualitatem.

Más allá de las Gorgades, las Islas de las Hespérides, según afirma Seboso, están retiradas a una distancia de cuarenta días de navegación hasta los profundos abismos del mar. Ciertamente, hemos oído que las Islas Afortunadas se encuentran frente a la izquierda de Mauritania; Juba dice que se encuentran, desde luego, al sur, pero próximas al ocaso. Me sorprende lo mucho que se espera de sus nombres, pero la realidad es inferior a la fama del vocablo. En la primera de ellas, cuyo nombre es Embrion, no hay ni ha habido edificaciones. Las cimas de los montes reciben la humedad de lagunas. Brotan cañahejas hasta la altura de árboles; de estas, las que son negras segregan al exprimirlas un líquido muy amargo, las blancas arrojan aguas apropiadas para beber. Aseguran que la otra isla se llama Junonia, en la cual hay un pequeño templo rematado de forma poco airosa. Se acerca a ella una tercera del mismo nombre, desprovista de todo. La del cuarto lugar se llama Capraria, más que repleta de enormes lagartos. Sigue Nivaria, de atmósfera nebulosa y compacta y aparte de ello cubierta siempre de nieve. Luego Canaria, llena de canes de mucha estatura, de los que dos fueron presentados al rey Juba. En ella se conservan restos de edificios. Gran cantidad de aves, bosques frutales, palmeras productoras de dátiles, mucha piña, generosa producción de miel, ríos abundantes en siluros. Dicen también que son lanzadas a ella por el mar agitado bestias marinas y posteriormente, cuando aquellos monstruos se pudren, lo infectan allí todo de un olor repugnante, y que, por lo tanto, la calidad de las islas no es congruente del todo con su nombre.

Salta a la vista la cercanía entre los dos textos, aun cuando Solino cambia el nombre de Ombrion por Embrion, menos apropiado, y Ninguaria por Nivaria, más cercano, en cambio, a la etimología propuesta, lo cual hace que sea el preferido a partir de ahí. Además, omite Invale y Planasia. Precisa más el aspecto del templete de Junonia y comenta lo inadecuado del adjetivo Afortunadas, sobre todo teniendo en cuenta el repugnante olor que provocan con su descomposición los animales marinos arrojados a la playa.

Un resumen de lo dicho por Solino ofrece, ya en el primer tercio del siglo V, Marciano Capela, otro escritor nacido en África (según Casiodoro era de Madaura, la misma ciudad natal de Apuleyo, hoy Mdaurusch, en Argelia); lo incluye la obra habitualmente titulada De nuptiis Philologiae et Mercurii y dice $(6,702)^{22}$ :

Vltra has Hesperidum insulae, quae in intimo admodum mari sunt. Fortunatas autem insulas in laeua Mauretaniae constitutas inter meridiem occasumque non dubium est: quarum prima Embriona dicitur, secunda Iunonia, tertia Teode, quarta Capraria, alia Niuaria, quae aere nebuloso et concreto est. Mox Canaria, canibus immensae magnitudinis plena: omnes auibus plenae, nemorosae, palmiferae, nuce pinea, mellis copia, amnibus ac siluris piscibus abundantes.

${ }^{22}$ Sigo la edición de Willis (1983). 
Más allá de estas (las Gorgades), las Islas de las Hespérides, que están en el mar profundo. En cuanto a las Islas Afortunadas, no hay duda de que se encuentran a la izquierda de Mauritania, entre el mediodía y el ocaso. A la primera de ellas se le llama Embriona, a la segunda Junonia, a la tercera Teode, a la cuarta Capraria, a otra Nivaria, la cual es de atmósfera nebulosa y densa; luego Canaria, llena de canes de enorme tamaño. Todas llenas de aves, boscosas, palmíferas, con piñas, cantidad de miel y abundantes en ríos y peces siluros.

Este texto se singulariza sobre todo por la aparición de esa isla Teode, que aceptarán más tarde otros autores. Ya Cl. Salmasius, en su voluminoso comentario a Solino, escribía al respecto (1629: 1313 B): Ridicula uero ac iocularis Martiani Capellae hallucinatio qui apud Solinum hoc loco legit. "tertia huic proxima, Teodem nomine». Atque hinc putauit nomen insulae fuisse Teodem: "Ridícula, verdaderamente, y chistosa la alucinación de Marciano Capela, que en este pasaje de Solino leyó tertia huic proxima, Teodem nomine. Y a partir de ahí pensó que el nombre de la isla era Teode». Es de notar que el verbo, no documentado antes de Apuleyo ${ }^{23}$, se usa relativamente poco; por otra parte, en el adverbio eode podía fácilmente haberse omitido la tilde que marca esa consonante final; en fin, la posterior adición de una $h$ en la inicial (Theode) viene a redondear el disparate, dado que así suena a transcripción del griego $\theta \varepsilon o ́ \varsigma$, , «ios». También se observa el cambio gramatical amnes siluris piscibus abundantes por amnibus ac siluris...: al convertir el sujeto en complemento circunstancial y añadir, en consecuencia, ac, extiende a todas las islas la abundancia de ríos.

Además de las que he citado hasta ahora, otros autores medievales hacen referencias, más o menos esporádicas, más o menos precisas, a las Canarias, siempre con la designación de Afortunadas ${ }^{24}$ y sin añadir nada nuevo. Así, los apuntes de Julio Honorio en su Cosmographia, escrita como pronto en el siglo IV, las incluyen en la lista de islas del océano meridional (41), por cierto, tras una Capraria, que el editor vincula con la pliniana ubicada en el mar Tirreno (nat. 3,81), quam Graeci Aegilion dixere, «a la que los griegos llamaron Egilio»; más adelante vuelven a mencionarlas a propósito del río Malva (47): Fluuius Malua nascitur sub insulas Fortunatas, circuiens extremam partem Mauretaniae, intercludens inter Barbares et Bacuates, uergit in mari quod appellatur Columnae Herculis: «el río Malva nace más abajo de las Islas Afortunadas, bordeando la parte extrema de Mauritania; cortando entre los Barbares y los Bacuates, se extiende hasta el mar que se llama de las Columnas de Hércules». Como se ve, pues, una mera constatación de su existencia y la ubicación geográfica.

El escepticismo, o la pura ignorancia, en relación con las Islas Afortunadas se prolongan a lo largo de los siglos, pese a los datos conocidos y divulgados a partir 6,3 y 8,19 .

${ }^{23}$ A él se deben las tres únicas veces que aparece la forma proximat en el PHI: met. 2,16;

${ }^{24}$ Parte de estos textos están recogidos y comentados en González Marrero - Aguiar Aguilar (2017-2018) y por Martínez Hernández, sin los originales griegos (1994a). 
al menos de la época imperial. Así, por ejemplo, el galo Eumenio, en su Panegyricus Constantino Augusto dictus, del año 310, escribe, evocando los límites del Orbe $(7,2)$ : Neque enim ille tot tantisque rebus gestis non dico Calidonum, aliorumque Pictorum siluas et paludes, sed nec Hiberniam proximam nec Thylen ultimam nec ipsas si quae sunt Fortunatorum insulas dignabatur acquirere: «Y él, realizadas tantas y tan grandes hazañas, no se dignaba ganarse, no digo los bosques y lagunas de los caledonios y otros pictos ${ }^{25}$, sino ni siquiera la cercana Hibernia, ni la remota Tule, ni las mismas Islas Afortunadas, si es que hay algunas».

Otros geógrafos ni las mencionan; la razón puede deducirse de lo dicho en la Expositio tutius mundi et gentium, también del siglo IV, versión manifiestamente mejorable de un original griego, que no se conserva, realizada por «Iunior filósofo», cuyo pobre latín trato de reproducir en español. Tras hablar de Hispania, el texto añade (59): Inde oceanum esse dicitur, et huius partem, quae nemo hominum narrare potest. Sed qui ibi esse potest? Est enim eremi solitudo et, sicut aiunt, est ibi finis mundi: «A partir de ahí se dice que está el Océano y su zona, de la que nadie en el mundo puede hablar. Pero ¿qué puede haber allí? En efecto es la soledad del yermo y, como dicen, allí está el fin del mundo».

De la confusión reinante en la Edad Media y su recurso a las fuentes antiguas, puede dar testimonio, ya en el siglo VII avanzado, la Ravennatis Anonymi Cosmographia, donde las noticias sobre las Islas Afortunadas se reducen a dos textos (cito por la edición de Pinder - Parthey 1860: IV 46): Ad partem denique occidentem habet ipsa Europa finem Oceanum [...] usque ad supra scriptum fretum quod diximus Septemgaditane, ubi est mons Statiola et insulae Fortunatae: «En fin, hacia la parte occidental tiene Europa el océano extremo, hasta el arriba mencionado estrecho al que llamamos Septemgaditano ${ }^{26}$, donde está el monte Statiola y las Islas Afortunadas»; y v 33:

Iterum in ipso Oceano, ut diximus, expleta parte occidentali, regredientes ad meridianam partem, litus Spaniae, juxta multotiens dictum fretum Septemgaditanum, dicuntur insulae, quarum nomina multis modis inuenimus. In ipso quippe meridiano Oceano, post Aethiopum patriam, diuersae existunt insulae, ex quibus aliquantas nominare uolumus, id est Azanasia, Pireon, Capriariam, Beathee, Theatrum, Nincaria, Lunonis, Scopolis, Thene.

Además, en el mismo océano, como dijimos, acabada la parte occidental, volviendo a la zona meridiana, la costa de Hispania, a la altura del muchas veces mencionado estrecho Septemgaditano, son mencionadas unas islas cuyos nombres hemos encontrado de muchas formas. Efectivamente, en ese mismo océano meridional, pasada la patria de los etíopes, existen diversas islas, de las cuales queremos nombrar algunas, o sea, Azanasia, Pireon, Capriaria, Beathae, Theatrum, Nincaria, Lunonis, Scopolis, Thene.

${ }^{25}$ Se refiere a los pueblos que habitaban el centro y norte de la actual Escocia.

${ }^{26}$ Es el Estrecho de Gibraltar, según leemos en III 12 qui fretus super scriptus Septemgaditanus diuidit, ut diximus, inter Mauritaniam et Ispaniam: «El estrecho Septemgaditano mencionado arriba marca la línea divisoria, como hemos dicho, entre Mauritania e Hispania». 
Aunque no estamos deteniéndonos especialmente en la nomenclatura, resulta evidente la amalgama de designaciones y las malas lecturas: así, por ejemplo, Scopolis puede indicar un genérico «de los escollos», o bien, a la vista de que es el único de estos nombres en ablativo plural, una interpretación del vocablo latino tomado por un

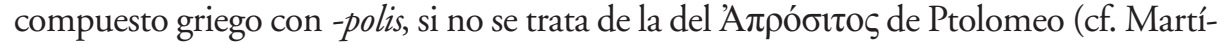
nez Hernández, 1994a: 254); Beatae, parece claro el genérico, reminiscencia de las Beatorum Insulae, que ya hemos visto en Jordanes; Capriaria, Nincaria y Lunonis se aproximan con claridad suficiente a Capraria, Ninguaria, y Junonia; incluso hay quien relaciona Azanasia (o Azauazia), que se acerca formalmente a Azores (cf. Martínez Hernández, 1994a: 254), con Ađ derían las Purpurariae.

Terminaremos esta selección con el Liber de mensura orbis terrae, obra del monje irlandés Dicuil «escrita en el año 825», la cual «es el vínculo que hay entre la Alta y la Baja Edad Media» (González Marrero - Aguiar Aguilar 2017-2018: 113)27. Ahí leemos, sin más, noticias tomadas expresamente de la Cosmographia (de Honorio) y de san Isidoro de Sevilla, la gran fuente de conocimientos para el mundo medieval $\left(7,5^{28}\right)$ :

Fortunatae atque Gorgodes Hesperidesque insulae quod sunt in occidentali pelago Africae multi nuntiant, longius ab Africa Gorgodes quam Fortunatae ac Hesperides quam Gorgodes. Quoniam in eo quod in Cosmographia fluuius Malua sub insula Fortunata nasci fertur, ex hoc prope ad Africam esse perhibetur. Distant autem Gorgodes a continente terra bidui nauigatione, ut in cuarto decimo libro Ethimologiarum Isidorus ait.

Las Islas Afortunadas, más las Gorgades y las Hespérides, muchos mencionan que están en el piélago occidental de África, las Gorgades más lejos de África que las Afortunadas y las Hespérides más que las Gorgades. Dado que en la Cosmografía se dice que el río Malva nace más debajo de una isla Afortunada, a partir de ahí se afirma que está cerca de África. Por su parte, las Gorgades distan del continente dos días de navegación, como dice Isidoro en el libro décimo cuarto de las Etimologías.

Y en 7,42-43 reproduce al pie de la letra el texto de Solino, después de una laguna, empezando por ferulae surgunt. La única variación digna de notar con respecto al original que nos ha llegado es el añadido a la descripción de Capraria transmitida por la edición que manejo: enormibus lacertis plus quam aliae referta: «llena más que otras de enormes lagartos».

En definitiva, pobre bagaje, que permite llegar a la conclusión del escaso interés real suscitado por una parte remota del mundo conocido, a la que solo se prestó

\footnotetext{
${ }^{27}$ A este monje le dedica un trabajo monográfico González Marrero (2010).

${ }^{28}$ Sigo la edición de Parthei (1870), con ligeras modificaciones de puntuación y Hesperidesque por Hesperides quae.
} 
verdadera atención, tratando de lograr alguna información aceptable según las costumbres imperantes, en los primeros tiempos del imperio romano. De no ser por la meritoria labor de Plinio, y sus fuentes, con todas las limitaciones y defectos que tiene, no habría a nuestro alcance más que vagas referencias a esas islas, situadas en una zona sobre la que, según los expertos, se perdió todo interés, político y mercantil, a partir de los siglos III-IV d. C., cuando se convirtió en el mare tenebrosum.

Y la situación se prolonga todavía durante siglos, pero esa es ya materia para otras instancias ${ }^{29}$.

\section{REFERENCIAS BIBLIOGRÁFICAS}

Con objeto de no alargar innecesariamente esta lista, baste señalar que, si no indico expresamente lo contrario, para los textos griegos y latinos recurro a las bases de datos Thesaurus Linguae Graecae y PHI Latin Texts (https://latin.packhum.org), de The Packard Humanities Institute, además de Cetedoc Library of Christian Latin Texts (CLCLT-3) CD-ROM: I Patres Latini. Biblia. II Medi Aevii Scriptores, dirigido por P. Tombeur, Turnhoult, Brepols, 1996. Los de geógrafos «menores» proceden de Müller (1882) y Riese (1878) respectivamente.

Correa Rodríguez, J. A. (2016): Toponimia antigua de Andalucia, EUS, Sevilla.

Fernández-Galiano, M. - Cristóbal, V. (2000): Horacio. Odas y Epodos, Cátedra, Madrid (3a ed.).

GARCíA GarCíA, A. Mª. (2007): Juba II, rey de Mauritania: traducción y comentario de sus fragmentos, Tesis doctoral, Universidad de La Laguna, Servicio de Publicaciones. [https://riull.ull.es/xmlui/bitstream/handle/915/9832/cs231.pdf.sequence=1\&isAllowed=y]

García García, A. Ma . (2009): «El informe de Juba II sobre las Fortunatae Insulae (Plinio el Viejo, HN, vI, 202-205)», Tabona 17: 141-161.

García García, A. Ma - Tejera Gaspar, A. (2014): «La primera imagen de las Islas Canarias en la Naturalis Historia de Plinio el Viejo», Fortunatae 25: 157-167.

García-Talavera Casañas, F. (2006): «Purpurarias, Afortunadas: la Macronesia Central en la Antigüedad", Makaronesia 8: 60-82.

GonZÁlez MARrero, J. A. (2008): «Fuentes latinas relacionadas con Canarias en la obra de Da Costa de Macedo", en F. Morales Padrón (coord.), Actas del XVII Coloquio de Historia Canarioamericana, Casa de Colón, Las Palmas de Gran Canaria: 238-248.

GonZÁlez Marrero, J. A. (2010): «Las islas atlánticas en el Liber de mensura orbis terrae del monje geógrafo irlandés Dicuil del siglo IX», Anuario de Estudios Atlánticos 56: 71-90.

González Marrero, J. A. - Aguiar Aguilar, M. (2017-2018): «De historia atlántica: un recorrido por los textos latinos y árabes medievales que mencionan las Islas Canarias", Fortunatae 28: 109-122.

${ }^{29}$ Puede verse un apunte de la situación en los siglos posteriores de la Edad Media en Martínez Hernández (1994b) y varios textos en Martínez Hernández (1994a). 
Martínez Hernández, M. (1992): Canarias en la mitología, Cabildo Insular de Tenerife y Centro de la Cultura Popular Canaria, Santa Cruz de Tenerife.

Martínez Hernández, M. (1993): «Sobre el plural Islas Canarias en la Antigüedad», en Strenae Enmanuelae Marrero Oblatae. Pars altera, Universidad de La Laguna, Servicio de Publicaciones, Cabildo Insular de Tenerife, Ayuntamiento de La Laguna, pp. 51-63.

Martínez Hernández, M. (1994a): «La onomástica de las Islas Canarias de la antigüedad a nuestros días", X Coloquio de Historia Canario-Americana, vol. 2, pp. 229-278.

Martínez Hernández, M. (1994b) «Sobre el conocimiento de las Islas Canarias en el Trecento: El De Insulis de Domenico Silvestri», Philologica canariensia 0: 239-279.

Martínez Hernández, M. (1996): Las Islas Canarias de la Antigüedad al Renacimiento. Nuevos aspectos, Cabildo Insular de Tenerife, Centro de Cultura Popular Canaria, Santa Cruz de Tenerife.

Müller, C. (1882): Geographi Graeci minores, vol. I, Didot, Paris.

Mynors, R. A. B. (1964): XII Panegyrici Latini, Clarendon, Oxford.

Pinder, M. - Parthey, G. (1860): Ravennatis anonymi Cosmographia et Guidonis geographica, F. Nicolau, Berlin.

Porcheron, P. (1688): Anonymi Ravennatis, qui circa saeculum VII vixit De Geographia libri quinque, S. Langronne, Paris.

RIESE, G. (1878): Geographi Latini minores, Henninger, Heilbronn.

PartheI, (1870): Docuili Liber de Mensura Orbis Terrae, F. Nicolai, Berlin.

Santana Santana, A. (2015): «El sistema geográfico de Marino de Tiro», Scripta Nova XIX (519): 1-35 [http://www.ub.es/geocrit/sn/sn-519.pdf].

Santana Santana, A. - Arcos Pereira, T. - Atoche Peña, P. - Martín Culebras, J. (2002): El conocimiento geográfico de la costa noroccidental de África en Plinio: la posición de las Canarias, Georg Olms, Zúrich-Nueva York-Hildesheim.

Santana Santana, A. - Arcos Pereira, T. (2003-2007): «La expedición de Juba II a las Islas Afortunadas y el meridiano cero del Orbis Terrarum", Orbis Terrarum 9: 143-158.

Salmasius, Cl. (1629): Plinianae exercitationes in Caii Iulii Solini Polyhistora. Pars altera, C. Morellus, Paris.

Silberman, A. (1988): Pomponius Mela. Chorographie, Les Belles Lettres, Paris.

Villeneuve, F. (1927): Horace. Tome I: Odes et Épodes, Les Belles Lettres, Paris.

Willis, J. (1983): Martiani Capellae De Nuptiis Philologiae et Mercurii, Teubner, Leipzig. 